\title{
USO DE OBJETOS INTELIGENTES DE APRENDIZAGEM COMO FERRAMENTA DA INFORMÁTICA NA EDUCAÇÃO
}

\section{USE OF INTELLIGENT LEARNING OBJECTS AS A TOOL OF THE INFORMATICS IN EDUCATION}

\author{
Allan Renato Sabino \\ Mestrando em Ciência da Computação pela Universidade Federal de Santa Catarina (UFSC) \\ E-mail: allanrenatosabino@gmail.com \\ Darlan Anschau \\ Mestrando em Ciência da Computação pela Universidade Federal de Santa Catarina (UFSC) \\ E-mail: darlan.anschau@gmail.com
}

\section{RESUMO}

O presente artigo apresenta um estudo sobre o uso de objetos inteligentes de aprendizagem, baseados em agentes na educação. Foi realizado um estudo exploratório sobre o fundamental teórico necessário para a confecção do referido artigo, podendo-se citar: o uso da informática na educação, o conceito de agentes e como os agentes podem ser utilizados para a criação dos objetos inteligentes de aprendizagem. A partir deste estudo, conclui-se que a inserção do computador na educação criou um novo paradigma de ensino. Nele, o uso de objetos inteligentes de aprendizagem, amparados pelo advento da inteligência artificial e dos seus agentes, fez com que os ambientes virtuais se tornassem inteligentes, respondendo melhor às necessidades dos educandos.

Palavras-chave: Informática na Educação. Agentes. Objetos Inteligentes de Aprendizagem.

\begin{abstract}
This article presents a study about the use of intelligent learning objects, based on agents in education. In which, there was made an exploratory study over the theoretical foundations necessary to weave this article, we might cite: the use of informatics in education, the agents concept and how they can be used to create these intelligent learning objects. Therefore, in this study, we might conclude that with the insertion of the computer in education has created a new tutoring paradigm. In it, the intelligent learning used in learning, supported by artificial intelligence and its agents, did that the virtual environments respond intelligently to the learners' needs.
\end{abstract}

Keywords: Informatics in Education. Agents. Intelligent Learning Objects. 


\section{INTRODUÇÃO}

Por muito tempo, de acordo com Araujo e Teixeira (2007, p. 4), os educadores vêm experimentando formas de equacionar suas teorias de ensino com o dia a dia na sala de aula. A informática, através do uso do computador, pode ser utilizada como uma ponte no estreitamento da relação entre teoria e prática. A versatilidade na manipulação do computador permite que o indivíduo possa vivenciar e realizar experimentos, produzir textos ou realizar pesquisas mais eficientemente em comparação com a metodologia tradicional, tornando-a, muitas vezes, arcaica. Além disso, o computador permite tanto a realização de operações individuais, onde o educando navega por assuntos do seu interesse, quanto à socialização através do relacionamento com pessoas distantes geográfica e culturalmente.

Quando se discursa acerca do uso do computador na educação, inicialmente, tende-se a acreditar que essa prática seja recente. Entretanto, segundo Meek e Ralston (1976, p. 272), a utilização de computadores na educação é tão remota quanto o advento comercial dos mesmos. Para os autores, esse tipo de aplicação sempre foi um desafio para os pesquisadores preocupados com a disseminação dos computadores na sociedade. Os autores ainda complementam que em meados da década de 1950, quando começaram a ser comercializados os primeiros computadores com capacidade de programação e de armazenamento de informação, apareceram as primeiras experiências do seu uso na educação.

No entanto, Valente (1999, p. 11) destaca que a ênfase dada nessa época era praticamente a de armazenar informação para depois transmiti-la ao aprendiz. Os autores também enfatizam que hoje, a utilização de computadores na educação é muito mais diversificada, interessante e desafiadora, do que, simplesmente, transmitir informação. $\mathrm{O}$ computador pode ser também utilizado para enriquecer ambientes de aprendizagem, auxiliando o educando no processo de construção do seu conhecimento. Para tanto, é utilizado o Objeto de Aprendizagem (OA). Um OA é descrito por Bavaresco, Silva e Silveira (2008, p. 20) como uma peça de software que proporciona algum tipo de experiência de aprendizagem.

O uso de OA causou uma quebra de paradigmas educacionais, onde não somente são utilizados ferramentais tradicionais (giz e quadro), mas também ambientes virtuais de ensino onde, muitas vezes de forma lúdica, o educando tem acesso a atividades extraclasse, além de interagir, em tempo real, com seus colegas de turma. Com o advento da Inteligência Artificial (IA) os ambientes virtuais evoluíram, tornando-se capazes, de forma autônoma, de interagir com o educando e propor suas atividades, baseando-se em seu desempenho (entre outras 
funcionalidades). Surgiram assim os OIA (Objetos Inteligentes de Aprendizagem), que se tratam de OAs com certa faculdade de raciocínio, sendo implementados através de agentes racionais. Não existe uma definição universalmente aceita para o termo agente. Vários autores propõem, de acordo com seus domínios de conhecimento, suas próprias definições. Dentre elas destaca-se a de Wooldridge (2002, p. 15). Para o autor, um agente é observado como um sistema computacional que está situado em algum ambiente e que, baseado na percepção do mesmo, é capaz de realizar ações, de forma autônoma, para alcançar seus objetivos. Um agente é considerado racional, de acordo com Russel e Norvig (2003, p. 23), quando, dado uma sequência de percepções do ambiente, ele é capaz de escolher, baseado em seu conhecimento, as ações que melhor satisfazem seu objetivo.

Embasado por esse arcabouço, o presente artigo visa descrever um estudo exploratório sobre os temas apresentados anteriormente e como eles influenciam no processo de aprendizagem. A seguir, na fundamentação teórica, será abordado como o uso do computador, através da criação de objetos de aprendizagem inteligentes, criou um novo paradigma de ensino.

\section{FUNDAMENTAÇÃO TEÓRICA}

Esta seção descreve, sucintamente, o ferramental estudado durante a confecção do presente artigo. Inicialmente, na seção 2.1, é descrito o uso da informática na educação. A seção 2.2 apresenta os objetos de aprendizagem. Em seguida, na seção 2.3, são introduzidos os conceitos acerca dos agentes. Por fim, na seção 2.4, são descritos os objetos inteligentes de aprendizagem.

\subsection{INFORMÁTICA NA EDUCAÇÃO}

Dentre as variáveis envolvidas no uso do computador na educação, de acordo com Magno et al (2004, p. 118), pode-se distinguir: aluno, professor, computador e o meio ambiente. Usar o computador implica em gerar representações e relações entre esses quatro elementos. Em muitas situações, pode haver a necessidade de se introduzir mais elementos no processo educativo. A interação entre o computador e o meio ambiente pode se dar de forma passiva ou ativa. Nas interações, o computador pode ler o ambiente em volta, através de sensores ou pode atuar sobre o meio ambiente, através do uso de motores. Essas ferramentas podem ser utilizadas 
de forma ampla no ensino de ciências onde, muitas vezes, há a necessidade de se realizar experimentos científicos, acompanhados pelo computador. Apesar da grande importância da interação entre o computador e o meio ambiente, em sala de aula, essa técnica muitas vezes fica subutilizada pela necessidade da aquisição ou construção de alguma infraestrutura auxiliar.

Para que o educador conduza o processo de educação com o uso do computador, no entendimento de Araujo e Teixeira (2007, p. 4), é necessário que este conheça as diversas formas de usar a máquina. Ele deve guiar-se com curiosidade, por entre os sites da internet e pelas novas formas de comunicação que surgem na rede mundial de computadores. É necessário também que ele esteja sempre atento ao que atrai os alunos nesse mundo virtual, onde inovações e novidades fazem parte da sua própria dinâmica. É importante salientar também que o educador saiba alertar os riscos e benefícios que a internet traz, estimulando os alunos a usarem a rede de forma cautelosa e em atividades que lhes proporcione crescimento. A liberdade que o mundo virtual oferece leva, necessariamente, a uma responsabilidade e bom senso da parte dos jovens que são introduzidos nesse mundo, cada vez mais cedo, necessitando ser conduzidos, adequadamente, nesse processo.

Araujo e Teixeira (2007, p. 4) descrevem que a intermediação entre o professor, o computador e o aluno passa, necessariamente, pelo software, que deve ser a ferramenta usada na mediação do conhecimento. Entendendo o software como ferramenta crucial, pode-se dividir os programas em duas categorias: uso geral e específicos para a educação. $\mathrm{Na}$ internet podem ser encontrados muitos programas gratuitos tanto para uso geral quanto específicos. Todavia, poucos são adequados à realidade de todos os professores. Principalmente quando tratam de locais longe dos grandes centros ou mesmo de culturas e sociedades marginalizadas. Muitas vezes surge o desejo ou mesmo a necessidade do profissional em adequar o programa à sua realidade. Essa adequação pode envolver a releitura do material usado dentro do contexto local, envolvendo a criação de novas ferramentas.

\subsection{OBJETOS DE APRENDIZAGEM}

Com o intuito de aproveitar o máximo do potencial dos conteúdos digitais, no âmbito educativo, surgiu um conceito que, de acordo com Guzmán (2005, p. 19), está causando mudanças radicais na forma de conceituar e criar conteúdo, recebendo a alcunha de OA. Para o autor, um OA é um elemento utilizado para instrução, ensino e aprendizagem baseados em computador, não se tratando propriamente dito de uma tecnologia e sim de uma filosofia. 
O Learning Technology Standards Committee (LTSC) (LTSC, 2005) caracteriza o OA como pequenos "pedaços" de conteúdo autocontidos voltados para a satisfação de um objetivo de aprendizado específico. Gomes, Silveira e Viccari (2004, p. 391) definem o OA como qualquer entidade, digital ou não, que possa ser usada, reutilizada ou referenciada em um processo de aprendizagem. Eles necessitam de metadados a fim de serem indexados, recuperados e reutilizados em repositórios. Os metadados consistem em um arquivo que descreve o conteúdo educacional em aspectos técnicos e educacionais. Bavaresco, Silva e Silveira (2008, p. 22) descrevem o OA como recursos de educacionais que podem ser utilizados no processo de aprendizagem suportada pela tecnologia, descritos formalmente por seus metadados, armazenado em um repositório e que podem ser combinados com outros OA para criar objetos maiores.

De acordo com Wiley (2002, p. 2), a ideia principal do OA é permitir aos designers institucionais a construção de pequenos componentes educacionais que possam ser reutilizados inúmeras vezes e em diferentes contextos aprendizagem, nos moldes da Programação Orientada a Objetos (POO). Esta ideia possibilita que os materiais de aprendizagem se tornem mais estruturados, organizados e que possam ser disponibilizados em diferentes formatos. $\mathrm{O}$ autor usa uma analogia para ilustrar essa ideia, comparando o OA com peças de Lego ${ }^{\circledR}$. Elas são utilizadas para construir peças maiores que, por sua vez, podem ser utilizadas para construir outras peças e assim por diante, como descrito pela Figura 1. Nesta, pode-se observar que o OA1 (vermelho) é combinado como OA2 (branco) e com o OA3 (verde) para a criação do OA4 (amarelo).

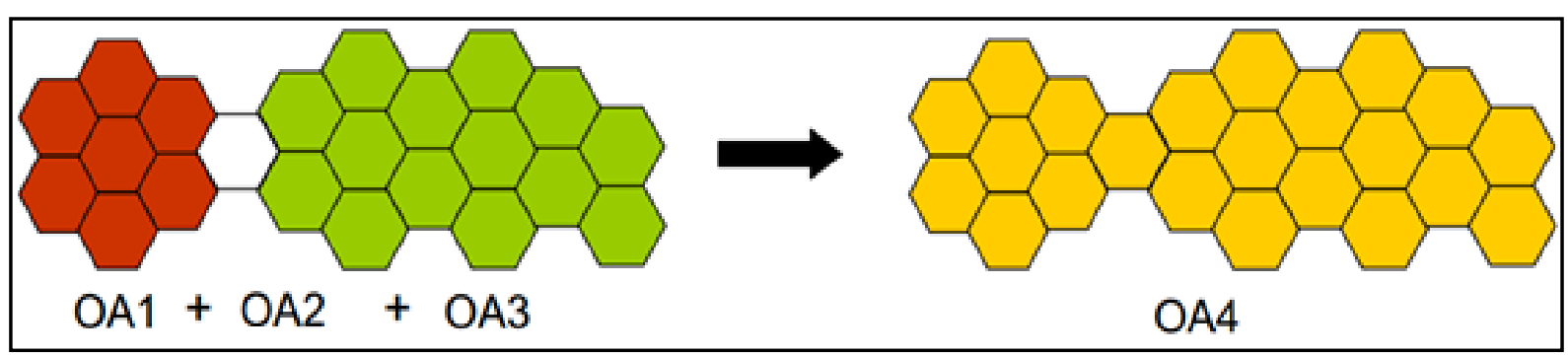

Figura 1 - Analogia do Lego ${ }^{\circledR}$

Fonte: adaptado de Guzmán (2005, p. 24).

Entretanto, Filho e Machado (2004) registram uma questão que, geralmente, é deixada à parte nos textos que definem o OA: o significado de aprendizagem e sua diferença do significado de ensino. Amoretti (2005, p. 203) discute que com frequência ensino e aprendizagem têm sido tratados como sinônimos, quando não o são. Um objeto que se limita a 
apresentar uma informação, mesmo tendo um objetivo educacional definido e claro, deveria ser classificado como objeto de ensino, deixando a definição de OA para os objetos que retornem algum tipo de resposta ao estudante, que lhe permita refletir sobre a reação do objeto.

Bavaresco, Silva e Silveira (2008, p. 25) descrevem algumas características dos OA, podendo-se citar: reusabilidade, adaptabilidade, granularidade, acessibilidade, durabilidade e interoperabilidade. A reusabilidade consiste em que eles devem ser reutilizados em diferentes ambientes de aprendizagem. Adaptabilidade descreve a capacidade dele se adaptar a qualquer ambiente de ensino. Um OA também deve ser acessível facilmente via internet para ser usado em diversos locais. Durabilidade consiste na possibilidade de que ele continue sendo utilizado com o passar do tempo, não sofrendo o peso da mudança da tecnologia. Um OA possui interoperabilidade quando é hábil de operar através de uma variedade de hardwares, sistemas operacionais e navegadores, realizando a comunicação, de forma transparente, entre diferentes OA. Gomes, Silveira e Viccari (2004, p. 391) têm o mesmo atendimento sobre essas características, elencando ainda que os mesmos devem ter capacidade de recuperação e avaliação.

Sobre a criação dos OA, pode-se discorrer acerca dos softwares de autoria. Software de autoria, de acordo com Araujo e Teixeira (2007, p. 4), é o nome genérico dado a classe de softwares destinados à produção de conteúdo para ambientes de aprendizagem. Para Maia (2002) um software de autoria deve ser um recurso amigável, para que leigos ou não programadores possam desenvolver com rapidez, amigabilidade e onde quer que estejam, independentemente de tempo, lugar ou situação física, um determinado OA.

Krieger (2013, p. 46) afirma que existem diversos softwares de autoria para conteúdo educativo. Entretanto, ele aponta e descreve, pelo fato de serem gratuitos e disponíveis online, os seguintes: Ardora, eXeLearning e Xerte. Ardora é um software que permite a qualquer professor criar as próprias atividades no formato Hyper Text Markup Language (HTML), a fim de serem utilizadas de forma simples, por seus alunos. O software permite criar atividades como: palavras cruzadas, preenchimento de lacunas, galeria de imagens, entre outras. eXeLearning é um software de autoria gratuito e de código aberto, utilizado para auxiliar os professores e acadêmicos a publicar conteúdo web sem a necessidade de conhecer HTML. Por fim, o Xerte é um ambiente de desenvolvimento para OA baseado em ícones. Isso permite que o conteúdo seja criado fazendo-se pouco uso de código fonte.

De acordo com Passarini (2003, p. 18), o fato de existirem diversos fabricantes de software de autoria no mercado, faz com que seja fundamental que os OA, produzidos com um software específico possam ser acessados através de outros softwares, promovendo assim a 
interoperabilidade. $\mathrm{O}$ autor complementa seu argumento afirmando que, para viabilizar a migração de conteúdos entre diferentes plataformas, foram criados diversos padrões. Estes padrões envolvem especificações que definem desde a geração dos metadados até as tecnologias utilizadas para a codificação dos conteúdos.

\subsubsection{Padrões de Metadados}

Metadados (dados sobre dados) são definidos, no âmbito dos OA, pelo LTSC (2005) como o conjunto mínimo de elementos necessários para que os OAs possam ser gerenciados, localizados e avaliados. Para Silva e Silva (2006, p. 3) eles representam a informação estruturada que descreve, explica e torna possível localizar e recuperar os OA. Segundo os autores, a função dos metadados é promover a identificação e possibilitar o compartilhamento, a integração, a utilização, a reutilização, o gerenciamento e a recuperação dos OA de maneira mais eficiente.

Os metadados, de acordo com Costa e De Marchi (2004, p. 2-3), podem ser comparados a um sistema de rotulagem que descreve o recurso, seus objetivos e características, mostrando como, quando e por quem o recurso foi armazenado, e como está formatado. Os metadados, para os autores, são essenciais para entender o recurso armazenado, descrevendo informações semânticas sobre o mesmo.

O desenvolvimento de padrões de metadados tem por objetivo, de acordo com De Pablo e Gárcia (2003, p. 1924): a) permitir aos estudantes e instrutores adquirirem, avaliarem e utilizarem recursos/objetos educacionais; b) compartilhar e intercambiar recursos/objetos educacionais por meio de qualquer sistema de aprendizado eletrônico; c) permitir o desenvolvimento de recursos/objetos educacionais em unidades que possam se combinar e decompor de maneira significativa; d) permitir que, por meio do computador, seja possível compor automaticamente lições personalizadas; e) fomentar o uso de padrões que assegurem que recursos/objetos educacionais possam trabalhar juntos dentro de uma filosofia de código aberto; f) facilitar o registro e a publicação final dos recursos/objetos existentes ou de novas associações aos recursos/objetos adicionais; g) incrementar o uso dos recursos/objetos educacionais, permitindo todas as formas de distribuição e uso: lucrativas, avaliativas e livres, assim como facilitar a segurança e autenticidade dos objetos; h) popularizar, ensinar e fomentar o uso de conteúdos e padrões educacionais em organizações públicas, privadas e governamentais; i) definir um padrão que seja simples e extensível a múltiplos campos de forma ampla e comumente aceita. 
No entendimento de Fabre, Tamusiunas e Tarauco (2003, p. 2) o uso de metadados traz benefícios relacionados à acessibilidade, interoperabilidade e durabilidade. Café, Catapan e Silva (2010, p. 96) afirmam que o uso de metadados, para a descrição dos OA, constitui uma excelente ferramenta para a documentação de tais objetos, provê uma organização para o repositório, permitindo a busca e localização por parte dos usuários dos OA. Para Guzmán (2005, p. 27), os metadados são especialmente úteis quando os recursos não são textuais e não podem ser indexados por sistemas automáticos como, por exemplo, recursos multimídia.

Café, Catapan e Silva (2010, p. 96-97) elucidam que para a escolha de metadados, com vista na descrição dos OA, é importante a adoção de padrões. De acordo com os autores, padrões representam um conjunto de regras e normas que especificam como se deve realizar um determinado serviço, como deve ser produzido determinado produto, ou como deve ser realizado determinado processo, visando garantir relativa qualidade e compatibilidade com outros produtos similares. Os autores complementam seu argumento afirmando que os padrões são definidos por meio de acordos internacionais, sendo normas estabelecidas por consenso mundial.

Vian (2010, p. 27) afirma que um padrão de metadados define as informações que permitem que um OA possa ser encontrado e reutilizado, juntamente com a obrigatoriedade e o domínio dos elementos do respectivo padrão. Para o autor, a quantidade e a organização dos elementos definidos por um padrão de metadados variam de acordo com a finalidade do padrão. Desta forma, existe a possibilidade de um mesmo conteúdo de aprendizagem ser descrito por mais de um padrão de metadados.

Os padrões de metadados, segundo Café, Catapan e Silva (2010, p. 97), buscam apresentar aspectos gerais do objeto, revelar aspectos técnicos para os desenvolvedores dos OA e mostrar aspectos pedagógicos úteis para professores e educadores. Com isso, o uso de padrões de metadados para descrever os OA, de acordo com Silva (2006, p. 58), passa a ter os seguintes propósitos: a) permitir aos estudantes e professores a pesquisa, avaliação, aquisição e a utilização dos $\mathrm{OA}$; b) permitir o compartilhamento e troca de $\mathrm{OA}$; c) permitir o desenvolvimento de $\mathrm{OA}$ em unidades que possam ser combinadas e decompostas de forma gerenciável; d) permitir a composição de lições personalizadas para aprendizes em particular; e) possibilitar que organizações educacionais, públicas ou privadas possam distribuir conteúdo educacional de forma padronizada; f) prover pesquisas que suportam o compartilhamento de recursos/objetos; g) definir um padrão simples e extensível a vários domínios; h) dar suporte de segurança necessária para a autenticação e distribuição de OA? 
No decorrer dos últimos anos, para Café, Catapan e Silva (2010, p. 98), esforços têm sido empreendidos no sentido de estabelecer padrões internacionais para facilitar o armazenamento e a recuperação dos OA. Os autores afirmam que esses esforços visam garantir a interoperabilidade dos $\mathrm{OA}$ nas diferentes plataformas, sem perda de conteúdos e funcionalidades. A partir dessa premissa surgiram iniciativas que visam o desenvolvimento de normas, padrões e especificações de metadados. Dentre as principais instituições, pode-se citar: Dublin Core Metadata Initiative (DCMI), Institute of Electrical and Electronics Engineers (IEEE) e International Standards Organisation (ISO). Uma descrição sucinta das mesmas é disposta no Quadro 1.

\section{Quadro 1 - Principais instituições mantenedoras de padrões de metadados}

\begin{tabular}{|l|c|}
\hline \multicolumn{1}{|c|}{ INSTITUIÇÃO } & REALIZAÇÃO \\
\hline DCMI & Desenvolvimento do padrão Dublin Core (DC) \\
\hline IEEE & Desenvolvimento do padrão Learning Object Metadata (LOM) \\
\hline ISSO & Desenvolvimento do padrão ISO 19788-2 \\
\hline
\end{tabular}

Fonte: Adaptado de Café, Catapan e Silva (2010, p. 98).

A seguir, no Quadro 2, Quadro 3 e Quadro 4, os padrões DC, LOM e ISO 19788-2, respectivamente, são descritos alguns atributos importantes. Os referidos quadros estão estruturados na forma: elemento do padrão de metadados e sua descrição. Embora cada padrão adote sua própria nomenclatura para o conjunto dos elementos que o compõe, é interessante salientar que os termos atributo, característica e segmento são equivalentes em sua semântica.

\section{Quadro 2 - Esquema Básico do DC (Versão 2000)}

\begin{tabular}{|l|c|}
\hline \multicolumn{1}{|c|}{ ATRIBUTO } & DESCRIÇÃO \\
\hline Identificador & Identificação não ambígua do recurso dentro de um dado contexto \\
\hline Colaborador & Entidade responsável pela contribuição ao conteúdo do recurso \\
\hline Cobertura & Extensão ou cobertura espaço-temporal do conteúdo do recurso \\
\hline Criador & Entidade principal pela elaboração do conteúdo do recurso \\
\hline Data & Data associada a um evento no ciclo de vida no recurso \\
\hline Descrição & Descrição sobre o conteúdo do recurso \\
\hline Formato & Manifestação física ou digital do recurso \\
\hline Linguagem & Idioma do conteúdo intelectual do recurso \\
\hline Publicador & Instituição responsável pela difusão do recurso \\
\hline Relação & Referência a outro recurso que se relaciona com o recurso em questão \\
\hline Direito & Informações sobre os direitos do recurso e de seu uso \\
\hline Fonte & Referência a outro recurso que tenha originado o recurso em questão \\
\hline Assunto & Assunto referente ao recurso \\
\hline Título & Título dado ao recurso \\
\hline Tipo de Recurso & Natureza ou gênero dado ao conteúdo do recurso \\
\hline
\end{tabular}

Fonte: Adaptado de Café, Catapan e Silva (2010, p. 99). 


\section{Quadro 3 - Esquema Básico do LOM (Versão Draft 2002)}

\begin{tabular}{|l|l|}
\hline \multicolumn{1}{|c|}{ CARACTERÍSTICA } & \multicolumn{1}{|c|}{ ELEMENTOS } \\
\hline Geral & $\begin{array}{l}\text { Reúne características gerais sobre o OA, tais como: identificador (catálogo, entrada), } \\
\text { título, idioma, descrição, palavra-chave, cobertura, estrutura e nível de agregação }\end{array}$ \\
\hline Ciclo de Vida & $\begin{array}{l}\text { Descreve a evolução, o estudo atual, e as diversas contribuições, tais como: versão, } \\
\text { status e contribuintes (papel, entidade e data) }\end{array}$ \\
\hline Meta-metadados & $\begin{array}{l}\text { Descreve os metadados que estão sendo utilizados, tais como: identificador } \\
\text { (catálogo e entrada), contribuintes (papel, entidade e data), esquema de metadados e } \\
\text { linguagem }\end{array}$ \\
\hline Técnica & $\begin{array}{l}\text { Reúne aspectos técnicos necessários para utilizar o objeto de aprendizagem, bem } \\
\text { como suas características próprias, tais como: formato, tamanho, localização, } \\
\text { requisitos, comentários sobre instalação, requisitos para outras plataformas e } \\
\text { duração }\end{array}$ \\
\hline Educacional & $\begin{array}{l}\text { Descreve aspectos educacionais e pedagógicos associados, tais como: tipo de } \\
\text { interatividade, tipo de recurso de aprendizagem, nível de interatividade, densidade } \\
\text { semântica, papel do usuário final, contexto, faixa etária, dificuldade, tempo previsto } \\
\text { para aprendizagem, descrição e linguagem }\end{array}$ \\
\hline Direito & $\begin{array}{l}\text { Relata condições de uso e aspectos da propriedade intelectual, tais como: custo, } \\
\text { direito de cópia e outras restrições e descrição }\end{array}$ \\
\hline Relação com Recurso & $\begin{array}{l}\text { Descreve como este objeto de aprendizagem está relacionado com outros OA, tais } \\
\text { como tipo e recurso }\end{array}$ \\
\hline Observação & $\begin{array}{l}\text { Reúne comentários sobre o uso educacional do OA e dados sobre a autoria dos } \\
\text { comentários, tais como: entidade, data e descrição }\end{array}$ \\
\hline Classificação & $\begin{array}{l}\text { Descreve como um OA enquadra-se em um sistema de classificação particular, tal } \\
\text { como: propósito, caminho taxonômico (identificador e entrada), descrição }\end{array}$ \\
\hline
\end{tabular}

Fonte: Adaptado de Café, Catapan e Silva (2010, p. 99).

\section{Quadro 4 - Esquema Básico do ISO 19788-2 (Versão Draft 2002)}

\begin{tabular}{|l|l|}
\hline \multicolumn{1}{|c|}{ SEGMENTO } & \multicolumn{1}{c|}{ ELEMENTOS } \\
\hline Descrição & $\begin{array}{l}\text { Reúne características gerais sobre o conteúdo de aprendizagem, tais como: } \\
\text { identificador, título, idioma, descrição, tipo de recurso, cobertura, estrutura, nível } \\
\text { de agregação e duração }\end{array}$ \\
\hline Ciclo de Vida & $\begin{array}{l}\text { Descreve a evolução, o estado atual, e as diversas contribuições feitas ao recurso, } \\
\text { tais como: versão, status e contribuintes (papel, entidade, data) }\end{array}$ \\
\hline Registro & $\begin{array}{l}\text { Fornece dados referentes ao identificador, repositório original, data das } \\
\text { atualizações, contribuintes (papel, entidade, data), perfil (nome, identificação) e } \\
\text { idioma }\end{array}$ \\
\hline Instanciação & $\begin{array}{l}\text { Define aspectos e características técnicas, tais como: formato, tamanho, } \\
\text { localização e requisitos técnicos }\end{array}$ \\
\hline Pedagógico & $\begin{array}{l}\text { Descreve aspectos de aprendizagem e pedagógicos associados ao contexto } \\
\text { (audiência, idade mínima e máxima, usuário final, idioma, tipo de instrumento } \\
\text { pedagógico, descrição pedagógica, dificuldade e tempo necessário), ao tipo e ao } \\
\text { nível de interatividade e a densidade semântica. }\end{array}$ \\
\hline Direito & $\begin{array}{l}\text { Relata condições de uso e aspectos de propriedade intelectual, identificando preço } \\
\text { e direitos de propriedade e uso }\end{array}$ \\
\hline Relação com Recurso & $\begin{array}{l}\text { Descreve como um objeto está relacionado com outros objetos de aprendizagem, } \\
\text { mostrando o tipo de relacionamento e recursos relacionados }\end{array}$ \\
\hline Observação/Anotação & $\begin{array}{l}\text { Reúne comentários sobre o uso educacional do recurso e dados sobre a autoria dos } \\
\text { comentários, tais como: participações (papel, entidade e data) e descrição }\end{array}$ \\
\hline Classificação & $\begin{array}{l}\text { Descreve como um recurso enquadra-se em um sistema de classificação particular, } \\
\text { indicando propósito, tipo, fonte da nomenclatura, caminho/trajeto da nomenclatura } \\
\text { (identificador e entrada) e descrição do sistema de classificação ou palavras chave }\end{array}$ \\
\hline
\end{tabular}

Fonte: Adaptado de Café, Catapan e Silva (2010, p. 100). 


\subsection{AGENTES}

Um agente, segundo Russel e Norvig (2003, p. 23), é uma entidade cognitiva ou uma abstração de algum dispositivo que pode perceber seu ambiente através de sensores e pode agir sobre este ambiente através de atuadores. Os autores classificam os agentes em, basicamente, três tipos: humano, robô e software. Um agente humano tem olhos, orelhas e outros órgãos como sensores e mãos, pernas, boca e outras partes do corpo como atuadores. Um agente robô tem câmeras e localizadores infravermelhos como sensores e vários motores como atuadores. Por fim, um agente de software tem cadeias de bits codificados como percepções e ações. Wooldridge (2002, p. 15) complementa esse conceito afirmando que um agente é um sistema computacional, situado em um ambiente, capaz de realizar ações, de forma autônoma, a fim de atender algum objetivo.

Para Brener, Hartmut e Zarnekow (1998, p. 29) um agente requer inteligência para realizar suas tarefas. Segundo Russel e Norvig (2003, p. 24), um agente racional ou agente inteligente é aquele que, dentre de todas as ações possíveis, escolhe a que irá melhor atender seu objetivo. De acordo com Wooldridge (2002, p. 16), agentes inteligentes são aqueles que têm, pelo menos, as seguintes características: autonomia, reatividade, proatividade e habilidade social. A autonomia significa ser capaz de funcionar e tomar decisões de forma independente. Reatividade é quando os agentes podem perceber seu ambiente e responder, em tempo hábil, as mudanças que ocorrem nele para satisfazer seus objetivos. Proatividade é quando os agentes são capazes de exibir um comportamento direcionado às suas metas, tomando iniciativa para satisfazer seus objetivos. A habilidade social em agentes é manifestada quando estes podem interagir com outros agentes para satisfazer seus objetivos.

Brener, Hartmut e Zarnekow (1998, p. 29) descrevem como características importantes de uma agente inteligente: raciocínio e mobilidade. O raciocínio, descrito através da inteligência, é formado por três componentes principais: base de conhecimento interna, capacidade de raciocínio baseada no conteúdo da base de conhecimento e a habilidade de aprender ou se adaptar às mudanças no ambiente. A mobilidade descreve a habilidade de um agente para navegar dentro de redes de comunicação eletrônica. A mobilidade reduz o carregamento da rede, pois um agente móvel não precisa reunir a informação que requer para cumprir suas tarefas enviando mensagens através da rede. Ele pode, ao invés disso, ir até o computador ou até os agentes que têm a informação de que precisa, o que ocasiona um carregamento simples da rede, realizado, localmente, no computador alvo. 
Para Giraffa (1999, p. 51), incorporar agentes a um programa educacional intensifica os aspectos pedagógicos desejáveis no mesmo. Esses agentes são aqueles que realizam tarefas auxiliares ligadas às atividades pedagógicas. Isto é, ajudam os estudantes a encontrar programas específicos, arquivos, diretórios, entre outros. Eles executam tarefas para o estudante ou para seu tutor. Podem desenvolver atividades em colaboração ou em competição com alunos, dependendo de seus objetivos. De acordo com Wooldridge (2002, p. 31), agentes podem ser animados, sendo, geralmente, personagens que facilitam o aprendizado em ambientes de aprendizagem baseados em computadores. Esses agentes têm entendimento suficiente do contexto de aprendizagem e do assunto, sendo capazes de realizar papéis úteis em cenários de aprendizagem. Para Giraffa (1999, p. 51), existem algumas motivações para usar uma apresentação animada, baseada em agentes, para propósitos de ensino e aprendizagem: a) adicionam poder expressivo às habilidades de apresentação do sistema; b) ajudam os estudantes a realizarem tarefas procedurais; c) servem como guia através dos elementos do cenário (simulações).

\subsection{OBJETOS INTELIGENTES DE APRENDIZAGEM}

A partir do momento em que se empregam agentes na criação de OA, têm-se os OIA. Conceitualmente, para Bavaresco, Silva e Silveira (2008, p. 25), um OIA é definido como um agente capaz de desempenhar o papel de um OA. No entanto, de certa forma, um OIA é um tipo especial de OA que possui características de agentes. Operacionalmente, segundo Bavaresco, Silva e Silveira (2008, p. 27), um OIA é um agente que pode gerar experiências de aprendizagem, apresentando características inerentes a esse processo, tais como: modularidade, interoperabilidade, capacidade de ser descoberto, e, a mais importante dentre elas: reusabilidade.

A utilização do paradigma de agentes para a construção de OA, para Gomes, Silveira e Viccari (2004, p. 391), apresenta inúmeras potencialidades. Uma delas diz respeito aos métodos de comunicação adotados por agentes. Um agente é capaz de se comunicar, através de troca de mensagens, utilizando uma linguagem de comunicação de alto nível denominada Linguagem de Comunicação de Agentes (LCA). No modelo de objetos de aprendizagem mais completo, o Sharable Content Object Reference Model (SCORM), a comunicação é feita através da passagem de parâmetros e chamadas de métodos, seguindo o paradigma da orientação a objetos. Isso resulta em uma comunicação bastante estatística, onde todas as possibilidades 
devem ser previstas, em tempo de projeto. O uso de uma LCA extrapola esta estaticidade dando uma dinâmica maior ao processo. Isso ocorre devido ao fato de as LCA serem baseadas em teorias capazes de dar mais semântica à comunicação. Ainda, o conteúdo das mensagens pode ser representado através de uma Linguagem de Conteúdo (LC), as quais são fortemente baseadas em formalismos lógicos. O resultado da comunicação através da união de LC e de LCA é potencialmente melhor do que a comunicação através da abordagem de orientação a objetos.

Outra possibilidade interessante, descrita por Gomes, Silveira e Viccari (2004, p. 391), está ligada à capacidade de aprendizagem que os agentes possuem. Um OA dotado desta capacidade pode adquirir novos conhecimentos e comportamentos no decorrer de sua existência, através da interação com outros alunos e até mesmo com outros OA. Assim, é possível que o OA evolua, tornando-se mais dinâmico. As possibilidades de aprendizagem são enormes, tais como: adquirir novos materiais educacionais que podem auxiliar o aluno e complementar a sua tarefa; adquirir informações sobre os alunos, como as suas preferências e estilos cognitivos, para poder se adaptar a estas e até mesmo aprender como se adaptar a elas; mudar o seu conteúdo educacional no sentido de se adaptar ao estudante; entre outros.

\section{CONSIDERAÇÕES FINAIS}

$\mathrm{Na}$ sociedade atual, o computador torna-se uma ferramenta crucial para o desenvolvimento dos indivíduos e a educação deve incorporar essa ferramenta. Com isso, os educadores devem se atualizar e buscar formas de utilizar o computador em sala de aula. Nesse sentido, a formação do profissional para atuar nessa sociedade implica em entender a aprendizagem como uma maneira de representar o conhecimento, provocando um redimensionamento dos conceitos conhecidos. Para tal, outro ponto que se deve entender são os papéis de cada um dos envolvidos nesse processo - professor, aluno, computador e ambiente - e a maneira como eles interagem entre si, durante o processo de ensino e aprendizagem.

$\mathrm{O}$ avanço da tecnologia impactou diretamente nas técnicas computacionais utilizadas. No início, o uso do computador na informática se restringia ao uso de documentos textuais e ambientes virtuais, extremamente simples, para que os educandos interajam entre si. A partir do advento da IA, ambientes cada vez mais inteligentes foram sendo criados. O uso de agentes para criar OA, possibilitou que eles se tornassem mais efetivos. Esse fato se deu porque os OIA interagem com os educandos, percebendo as intenções e utilizam sua inteligência para dar as melhores respostas, dentre as conhecidas por eles. 


\section{REFERÊNCIAS}

AMORETTI, Maria S. M. et al. Objetos de aprendizagem funcionais e as limitações dos metadados atuais. In: SIMPÓSIO BRASILEIRO DE INFORMÁTICA NA EDUCAÇÃO, 16. 2005, Juiz de Fora. Anais... Juiz de Fora: SBIE, 2005. p. 201-210.

ARAUJO, Alberto E. P.; TEIXEIRA, Núbia P. C. Informática e educação: uma reflexão sobre novas tecnologias. Hipertextus Revista Digital, Garanhuns, v. 1, n. 1, p. 148-156, jan. 2007.

BAVARESCO, Natanael; SILVA, Júlia M. C.; SILVEIRA, Ricardo A. Projeto e desenvolvimento de um sistema multi-agentes para objetos inteligentes de aprendizagem baseados no padrão SCORM. Revista Brasileira de Informática na Educação, Porto Alegre, v. 16, n. 1, p. 19-27, jan./abr. 2008.

BRENER, Walter; HARTMUT, Wittig; ZARNEKOW, Ruediger. Intelligent software agents: foundations and applications. Berlin: Springer-Verlag, 1998.

CAFÉ, Ligia; CATAPAN, Araci H.; SILVA, Edna L. Os objetos educacionais, os metadados e os repositórios na sociedade da informação. Ciência da Informação, Brasília, v. 39, n. 3, p. 93-104, ago. 2010.

DE MARCHI, Ana C. B.; COSTA, Antônio C. da R. Uma proposta de padrão de metadados para objetos de aprendizagem de museus de ciências e tecnologia. RENOTE: Revista Novas Tecnologias da Educação, Porto Alegre, v. 2, n. 1, p. 1-10, mar. 2004.

DE PABLO, Víctor L.; GARCÍA, Victor M. Metadados de objetos educacionais. In: INTERNATIONAL CONFERENCE ON MULTIMEDIA AND INFORMATION \& COMMUNICATION TECHONOLOGIES IN EDUCATION, 2., 2003, Badajoz. Proceedings... Badajoz: Consejería de Educación, Ciencia y Tecnología, 2003. p. 1922-1926.

FABRE, Marie-Christine J. M.; TAMUSIUNAS, Fabrício R.; TAROUCO, Liane M. R. Reusabilidade de objetos educacionais. RENOTE: Revista Novas Tecnologias da Educação, Porto Alegre, v. 1, n. 1, p. 1-11, fev. 2003.

FILHO, Clovis; MACHADO, Elian de C. O computador como agente transformador da educação e o papel do objeto de aprendizagem. [S.1.], 2004. Disponível em: $<$ www.universiabrasil.net/ead/materia.jsp?id=5939>. Acesso em: 22 fev. 2015.

GIRAFFA, Lucia M. M. Uma arquitetura de tutor utilizando estados mentais. 1999. $157 \mathrm{f}$. Tese (Doutorado em Ciência da Computação) - Programa de Pós-Graduação em Ciência da Computação, Universidade Federal do Rio Grande do Sul, Porto Alegre.

GOMES, Eduardo R.; SILVEIRA, Ricardo A.; VICCARI, Rosa M. Objetos inteligentes de aprendizagem: uma abordagem baseada em agentes para objetos de aprendizagem. In: SIMPÓSIO BRASILEIRO DE INFORMÁTICA NA EDUCAÇÃO, 15., 2004, Juiz de Fora. Anais... Juiz de Fora: SBIE, 2004. p. 389-398.

GUZMÁN, Clara L. Los repositorios de objetos de aprendizaje como soporte a un entorno e-learning. 2005. 152 f. Tese (Doutorado em Processos de Formação em Espaços Virtuais) Programa de Pós-Graduação em Processos de Formação em Espaços Virtuais, Universidade de 
Salamanca, Salamanca. Disponível em: <http://gredos.usal.es/jspui/bitstream/10366/56649/1/ DIA_Repositoriosobjetos.pdf.pdf $>$. Acesso em: 25 fev. 2015.

KRIEGER, Juliano de S. Ferramenta de autoria de objetos de aprendizagem para televisão digital. 2013. 141 f. Dissertação (Mestrado em Ciência da Computação) - Programa de Pós-Graduação em Ciência da Computação, Universidade Federal de Santa Catarina, Florianópolis.

LTSC. WG12: learning object metadata. [S.1.], 2005. Disponível em: <ltsc.ieee.org/wg12/>. Acesso em: 9 fev. 2015.

MAIA, Carmem. Ferramentas aliadas. [S.1.], 2002. Disponível em: <www.universia.com.br/ materia/materia.jsp?id=970>. Acesso em: 12 fev. 2015.

MAGNO, Walter C. et al. Experimentos didáticos com o sistema de som de um PC. Revista Brasileira de Ensino de Física, Porto Alegre, vol. 26, n. 2, p. 117-123, jun. 2004.

MEEK, Chester L.; RALSTON, Anthony. Encyclopedia of computer science. New York: Petrocelli, 1976.

PASSARINI, Rosane Fátima. Objetos de aprendizagem: protótipo para módulo de ambiente de treinamento online. 2003. 105 f. Dissertação (Mestrado em Ciência da Computação) Programa de Pós-Graduação em Ciência da Computação, Universidade Federal de Santa Catarina, Florianópolis.

RUSSEL, Stuart J.; NORVIG, Peter. Artificial inteligence: a modern approach. 2nd ed., New Jersey: Prentice Hall, 2003.

SILVA, Eli L. Uma experiência de uso de objetos de aprendizagem na educação presencial: ação-pesquisa num curso de sistemas de informação. 2006. 144 f. Dissertação (Mestrado em Educação) - Programa de Pós-Graduação em Educação, Pontifícia Universidade Católica de Minas Gerais, Belo Horizonte, 2006.

SILVA, Patrícia A.; SILVA, Alberto R. Análise funcional de plataformas de objectos de aprendizagem. In: IBEROAMERICAN CONGRESS ON TELEMATICS, 6., 2006, Monterrey. Proceedings... Monterrey: CITA, 2006. p. 1-10.

VALENTE, José A. Informática na educação do brasil: análise e contextualização histórica. In: VALENTE, José A. (Org.) et al. O computador na sociedade do conhecimento. Campinas: Universidade Estadual de Campinas, 1999. p. 11-30.

VIAN, Jonas. Sistema multiagente para a indexação e recuperação aplicado a objetos de aprendizagem. 2010. 87 f. Dissertação (Mestrado em Ciência da Computação) - Programa de Pós-Graduação em Ciência da Computação, Universidade Federal de Santa Catarina, Florianópolis.

WILEY, David A. Connecting learning objects to instructional design theory: a definition, a metaphor, and a taxonomy. In: WILEY, David A. (Ed.). The instructional use of learning objects. Bloomington: Agency for Instructional Technology, 2002. p. 1-21.

WOOLDRIDGE, Michael. Introduction to multiagent systems. New York: Wile 